\title{
COVID-19 y el trasplante de órganos
}

\author{
COVID-19 and organ transplantation \\ María del Carmen Gracida-Juárez, * Federico Javier Juárez-de la Cruz ${ }^{\ddagger}$ \\ * Ex-jefa del Departamento de Trasplantes del Hospital de Especialidades del Centro Médico Nacional Siglo XXI, IMSS. \\ ‡ Hospital Ángeles Torreón.
}

En México al igual que en el resto del mundo, el trasplante de órganos es un tratamiento bien establecido para atender insuficiencias orgánicas terminales; en algunos casos representa el único tratamiento para salvar la vida de los pacientes, con órganos provenientes de donantes fallecidos. El trasplante de órganos se ha visto afectado ante la pandemia del COVID-19, producto de un virus desconocido hasta diciembre del 2019, cuyo primer caso se presentó en China. Al tratarse de una enfermedad infecciosa emergente, desconocer el comportamiento del virus y no contar con tratamiento eficaz una vez instalada la infección, ni la posibilidad de llevar a cabo inmunización masiva mediante vacunación, la práctica médica y quirúrgica del trasplante se ha visto afectada por la pandemia.

La aparición del virus SARS-CoV-2, causante de la enfermedad COVID-19, ha cambiado de manera radical la vida alrededor del mundo, las medidas tomadas para evitar el contagio por los diferentes países, la forma de ejercer la medicina ante unidades de cuidados intensivos saturadas por pacientes con COVID-19, la conversión de hospitales completos para la recepción de estos pacientes y la construcción de centros exclusivos para su tratamiento han sido sólo algunas de las medidas extremas tomadas para el control de esta pandemia, sin dejar de mencionar el impacto económico y social en la gran mayoría de países que han sufrido esta pandemia. El estilo de vida se ha visto afectado de manera radical ante las medidas de confinamiento y distanciamiento social.

En el último registro de la Organización Mundial de la Salud del día 20 de junio del 2020, en el repor- te número 152 , el número de casos confirmados por COVID-19 es de 8,525,042 y la mortalidad global de 456,973 pacientes, ${ }^{1}$ esta situación ha creado la necesidad urgente de investigación para el desarrollo de una vacuna segura, con un proceso a nivel global de ensayos clínicos y protocolos coordinados para el desarrollo de éstas.

La práctica de la medicina se ha visto afectada por la pandemia, dejando de lado cirugías y tratamientos no urgentes en pacientes ya programados para algún procedimiento quirúrgico. El trasplante de órganos sólidos y tejidos se encuentra entre los primeros lugares de las especialidades que más han sufrido las consecuencias de la pandemia, ante una infección emergente que representa una amenaza de transmisión tanto para los equipos médicos como para los receptores y donadores en vida de órganos.

La falta de garantía de espacios hospitalarios libres de COVID-19 en muchos países ha hecho que la práctica de trasplante de órganos sólidos se vea disminuida 0 abolida ante la falta de conocimiento del comportamiento del virus. En consecuencia, esta debacle ha reducido drásticamente la donación de órganos a partir de donante fallecido y de donante vivo, a la vez, han favorecido que pacientes en listas de espera se deterioren o fallezcan y que el número de pacientes aumenten progresivamente a causa de la falta de trasplantes.

En México, debido a la conversión de los hospitales para tratamiento de pacientes con COVID-19, las unidades de trasplantes con mayor número de procedimientos en el país se han visto afectadas por la ne- 
cesidad de suspender los programas de manera temporal durante la contingencia.

Es oportuno mencionar que el Centro Nacional de Trasplantes (CENATRA) ha trabajado a distancia con todos los expertos en trasplantes de órganos para la toma de decisiones en relación a la actividad de trasplantes, establecer protocolos a seguir para el reinicio de manera segura, además de iniciar un registro de pacientes trasplantados con COVID-19 en los diferentes Centros de Trasplante del país, conocer la evolución de los mismos y la tasa de mortalidad ocurrida. ${ }^{2}$

Sin duda, esta pandemia habrá de dejarnos no sólo enseñanzas en el ámbito de la salud, sino también lecciones profundas de economía mundial, impacto medio ambiental, interacción de gobiernos y lo más importante de todo será darnos cuenta que seguimos siendo seres frágiles en asuntos biológicos.

En este suplemento especial de la Revista Mexicana de Trasplantes, dedicado a COVID-19 y Trasplantes, un grupo de expertos revisan los aspectos más importantes del virus desde su biología y la historia de las infecciones virales, epidemiología y diagnóstico clínico para tener un mayor conocimiento acerca de esta nueva enfermedad y el tratamiento en pacientes con trasplante de órganos, cuáles son las medidas preventivas ante esta infección emergente, trasplante renal pediátrico, trasplante de hígado y trasplante de córnea.

Otros aspectos de importancia son el HLA y la infección por COVID-19, los aspectos éticos y la pandemia y el registro del Centro Nacional de Trasplantes (CENATRA) de COVID-19 en pacientes trasplantados.

\section{REFERENCIAS}

1. Reporte \#152 Publicado: Sábado 20 Junio, 2020. Available in: https://www.who.int/docs/default-source/coronaviruse/situationreports/20200617-covid-19-sitrep-149.pdf?sfvrsn=3b3137b0_4.

2. CENATRA (Centro Nacional de Trasplantes) Disponible en: www.cenatra.gob.mx.

Correspondencia:

Dra. María del Carmen Gracida-Juárez

E-mail:mcgracida@gmail.com 